\title{
THE HYPERTEXTUAL GATEWAY OF ELITE CHINESE UNIVERSITIES: A GENRE ANALYSIS OF THE “ABOUT" WEBPAGES
}

\author{
Ying Qi WU $\mathbf{W}^{1}$ \\ Cecilia Yin Mei CHEONG ${ }^{2 *}$ \\ Faculty of Languages and Linguistics, University of Malaya \\ 956791312@qq.com ${ }^{1}$ \\ ceciliac@um.edu.my ${ }^{2}$
}

Manuscript received 7 July 2020

Manuscript accepted 16 October 2020

*Corresponding author

https://doi.org/10.33736/ils.2365.2020

\begin{abstract}
This article reports a genre study of the "About" webpages published in the websites of nine elite Chinese universities (the C9 League). This study explored the macrolevel rhetorical structure and communicative purposes, followed by a micro-level discussion of the discursive strategies employed in this institutionalised genre. The findings reveal a dynamic interweaving of two distinct discursive resources linguistic and multimodal - rhetorically organised through the interplay between the mixing of thirteen move types and various interdiscursive elements. The analytical results indicate that the trend of marketisation, other than a predominant rhetorical feature of being informative, indeed influences the institutional web structuring through employing branding strategies to promote academic excellence as well as strengthen relationship with web readers. The dynamic interactions unfolded by this research not only deepen users' knowledge of a previously undiscovered yet discursively complex web genre, but also contribute to theoretical and methodological development in genre studies in this digital era.
\end{abstract}

Keywords: Genre analysis; rhetorical move; hypertextuality; "About" webpages; university

\section{Introduction}

Academic institutions, particularly represented by public universities, for a long time, are considered as the pinnacle of learning knowledge, and the predominant job of the universities is providing the best tertiary education to the learners and serving the society development (Osman, 2008). In the era of information, the World Wide Web contributes to distributing learning and information resources to 
numerous students, as well as supporting dialogue and collaboration within a dispersed community of education (O'Reilly \& Newton, 2000). The contemporary World Wide Web profoundly changes the communicative practices of higher education institutions (HEIs). In this regard, the usage of the online discourse is an integral part of the universities' daily routine to widen the margin of higher education and exert a pull on the students for admission (Bano \& Shakir, 2015; Caiazzo, 2013; Erhan \& Semira, 2010). The globalisation and marketisation of higher education are greatly organised owing to increasing geographical mobility and the universal infiltration of English as the language of marketing and education. The acknowledged interpretation of the university website is that it is the first page which is viewed by the outsiders, therefore they are presenting the university "virtual face" or as a valuable gateway to the audience (Caiazzo, 2013, p. 12). The use of university website plays a crucial role in creating a prestigious university identity, publicising university missions, as well as attracting potential students in the competitive marketisation of tertiary education in the present 21st century of globalisation (Fletcher, 2006). Grasping the knowledge of this university web discourse is therefore a vital key to understand how the universities position themselves and operate professional practices (O'Reilly \& Newton, 2000; Zhang \& O'Halloran, 2012).

\section{Hypertextuality}

The internet radically changes the relationship between readers with online discourses, the method of text production, and the ways of comprehension. The website is no longer simply a device, by contrast, it is a medium that provides readers with a set of novel media forms and genres (Gervais, 2013). In webmediated discourses, intertextuality can be manifested in diverse manners via explicit reference to other textual resources, in which the use of hyperlinks is regarded as one of the fundamental characteristics of the contemporary Internet society (Deuze, 2001). The hypertextual connections encompass site-internal and site-external, in which the former relates to the hyperlinks connecting parts within the same webpages/website, on the other hand, the site-external refers to connecting sub-pages from different webpages/websites. This hypertextual connectivity of different internal and external sources enables web users to access to multiple social voices and information (Bargiela-Chiappini, 2006). It also alters the conventional, linear reading mode in which the audience interact with texts (Kress, 2010). In the case of web reading, the online users have various pathways (Lemke, 2002) to choose from rather than following a sequence predetermined by the content producers. Thus, the multisequential hypertexts encourage users to actively get involved in meaning making and therefore increase the interactivity between information producers and readers (Lam, 2013).

Hypertextuality is regarded as a ubiquitous form of discourse in contemporary web contexts, whereas the understanding of it remains deficient. The previous theories and analytical models for investigating communication have frequently been established for language and traditional forms of media. Nevertheless, the continuous development of interactive digital technology has 
revealed new theoretical challenges, particularly with regard to the integration of linguistic elements with other resources (e.g. visual images, hyperlinks) in dynamic hypertextual conditions. Although some academic investigations shedding some light on generic structures and hypertextual features of online genres have been identified in recent decades (Askehave \& Nielsen, 2005; Suen, 2013; Zhang \& O'Halloran, 2012), the focus and analysis are specifically intended to address homepages of institutions. Nevertheless, the functions and distribution of hypertextual construction of non-homepage within and across web genres remain a largely unexplored area. Henceforth, this article is intended as a genre-based investigation to examine the rhetorical features of the "About" webpages of Chinese universities, with a purpose to unfold the identification of emerging conventions that characterise institutional communicative practices in the hypertextual web context.

\section{"About" Webpage as a Hypertextual Genre}

The "About" or "About Us" webpage is an autobiographical, educational and personal description of the website. This webpage reveals the background and history of the company/institutions, and presents the business/information to visitors or customers (Tan, 2013). The "About" webpage is usually regarded as an introductory section that aims at introducing and describing "profile" of companies, institutions, and individuals (Bano \& Shakir, 2015, p. 133). Additionally, it sets trust and loyalty, as well as differentiates companies from their competitors (CasañPitarch, 2015). Today, both profit and non-profit making organisations deploy the "About" webpages to engage themselves with their audience in a personal way (Nutter, 2009). In universities' websites, in addition to offering a brief description of the characteristics and information of the universities, the "About" webpage is intended to shape what may be conceived as an explicit "narration" of how the university wishes to be perceived by others.

The "About" webpage is formed by one single page consisting of a number of sub-pages and elements which jointly form a suitable text to present the company or the individual (Graham, 2013). Furthermore, Graham (as cited in Casañ-Pitarch, 2015) summarised some conventionalised information that an "About" page should:

(1) introduce and explain how the institution started; (2) state the origin of the business; (3) tell the story behind the products: how they are made and designed; (4) share creative inspiration for the institution's products and management; (5) present the institution's or owner's background experience with the aim of establishing instant credibility; (6) discover the institution's vision, dreams, and aspirations; and (7) link work, values and beliefs with motivation. (p. 71)

However, it is also possible to see "About" pages constituted by distinct sections, as Lam (2009) suggested a variety of possible sub-sections that enable a complete typical "About" page of business companies, for instance, sections of Contact Information, FAQs, etc. 
The language used on university web genres, especially on the "About" webpages, received much attention by the early researchers who aimed to identify the emerging conventions that characterise institutional communicative practices in the web-mediated contexts (Caiazzo, 2013). In the study of Caiazzo (2014), the linguistic characterisations of the "About" webpages of British universities have been qualitatively analysed in terms of the heading of sections, diatypic variability (welcome messages and informative content), text length, and the role played by the navigation options as further sources of information. The results show that although communicative practices of the universities still leave room for a diversity of individual choices, some emerging conventions are identified in the verbal presentation of the "About" webpages. The promotional feature is also uncovered in the "About" discourses in that the marketisation increasingly permeates contemporary discursive practices in some contexts of higher education (e.g. British universities) (Morrish \& Sauntson, 2013). The process of commodification within universities is mirrored at some "About" sections, in which the textual elements are used to achieve the communicative purpose of showing promotional nature of universities (Villanueva, Dolom, \& Belen, 2018).

Based on what has been reviewed so far, it shows that there is worth concentrating on the generic investigation to find out the way how the "About" webpage is constructed, used and understood, then what linguistic or non-linguistic features are used to construct its rhetorical structure to make it as a characteristic hypertextual web genre. With this objective in mind, the researchers draw on a particular genre-based approach to answer two research questions: (1) what is/are the communicative purpose(s) of the Chinese universities' "About" webpages? (2) What are the generic and interdiscursive characteristics of Chinese universities' "About" webpage?

\section{Methodology}

\section{Data}

This study aims at figuring out how Chinese universities organise their "About" webpages as an efficient gateway to show themselves to outsiders. The dataset was compiled from nine Chinese universities which are identified as the C9 League universities: Fudan University (FDU), Harbin Institute of Technology (HIT), Nanjing University (NJU), Peking University (PKU), Shanghai Jiao Tong University (SJTU), Tsinghua University (THU), University of Science and Technology of China (USTC), Xi'an Jiaotong University (XJTU), and Zhejiang University (ZJU). The selection of data was determined according to the reputation and profile of universities among the large database in China. Previous survey has indicated that there should be a particular focus on "investigation using smaller datasets for more qualitative and more delicate analysis" (Bednarek, 2014, p. 141). The C9 League universities admit more elite groups of students and academic experts than other higher educational institutes in China so that they are greatly dedicated to becoming academically renowned universities (Han, 2014; Xiong, 2012). On the whole, the C9 League has 
the fastest growth rate among its Western peers (e.g. Ivy League, Go8, U15, Russell Group) and it shows a trend to continue this increasing pace, and there is a great possibility that the C9 League may eventually catch up with the other peer groupings around the world in the near future (Allen, 2017). It is widely acknowledged that the C9 League to the greatest extent represents the highest academic and educational achievements of China's higher education to the world (Allen, 2017; Fang et al., 2013; Han, 2014; Xiong, 2012; Yang \& Xie, 2015; Yue \& Zhu, 2009). It is, therefore, important to investigate the effectiveness of such universities in their attempt to organise their web-mediated genres. All the nine "About" webpages that are published in English were collected and saved as data corpus between August 2019 and September 2019 before the next freshman registration.

\section{Data Analysis}

Osman $(2005,2008)$ has investigated universities' brochures as a professional genre from two perspectives: the applied linguistics perspective and the ESP practice perspective. Due to the similarity of data sources, the rhetorical structure of universities' brochures proposed by Osman $(2005,2008)$ was adopted as a preliminary framework in analysing rhetorical move structure of the "About" webpages in this study. In regard to data analysis, we first identify the "About" webpages in terms of the move structures based on Osman's $(2005,2008)$ movestep analytical framework as well as the previous genre investigations (Cheong, 2013; Suen, 2013). To begin with, a tentative coding scheme was developed on the basis of these analytical frameworks and studies, which was used to pilot code a representative sample of one university's "About" webpage to test its credibility. Following, this pilot code sample was subsequently checked by another expert who had done prior rhetorical analysis of web-mediated genres to ensure its viability. During the process of discussion and modification, some move types were combined or removed meanwhile new categories emerged (Teo \& Ren, 2019). This process of securing inter-rater reliability assisted in achieving reliability and trustworthiness of the study. Then, the micro-level constituent steps (discursive strategies) realising each macro-level rhetorical move were discussed (Askehave \& Nielsen, 2005). Last, the communicative purposes of the rhetorical moves of the "About" genre were unpacked based on the qualitative analysis.

\section{Analyses and Results}

\section{Overview Features of the "About" Genre}

Heading of a specific web page has defined as a "genre marker", which is one of those "distinctive expressions and devices that are utilised to structure a text from a particular genre" (Biber \& Conrad, 2009, p. 54). A variety of headings are used by the universities to address this type of webpage, in which the preferred choice involves "About" in most cases ( $89 \%$ or $8 / 9$ ) except XJTU. There is a propensity for the 
universities to deploy "About" (44\% or 4/9) or "About + university name" (33\% or $3 / 9)$. Moreover, the other minimally used titles also retain as a distinctive feature of this "about" (i.e. About Us, University + introduction). As a consequence, the heading of "About" is used to refer to this specific webpage throughout this article.
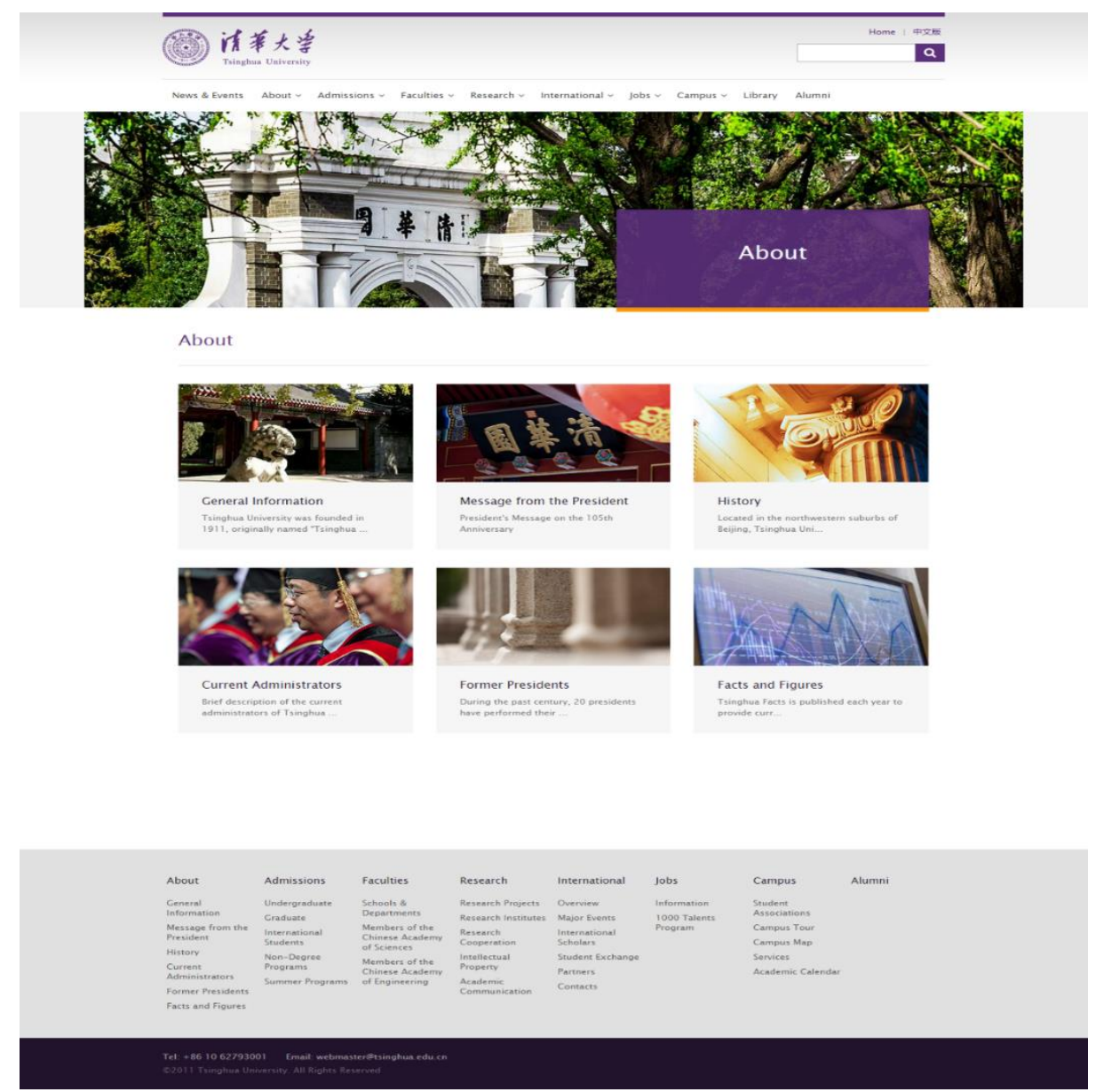

Figure 1. "About" Main Page of THU

All the nine "About" webpages are accessed from the universities' homepages through a link placed in a horizontal bar menu. The nine "About" pages are designed as a separate webpage which encompasses several sub-pages. It was observed that the first page (see Figure 1) appearing after clicking the "About" option tend to imitate universities' homepages, which serves as an indicator concerning with general content, sub-pages and lay-out of the "About" webpages. In order to differentiate with website homepages, this page is defined as "About" main page which is designed by five universities (56\%) as the first page of their "About" webpages: FDU, NJU, THU, USTC and ZJU. This "About" main page still reveals the similarity between the website homepages and the book exordium in that it "displays an interesting mixture of promotional features intertwined with content information where texts, visuals, sound, and animation are combined with enticing summaries of web site contents to make the user stay and explore the site"

The Hypertextual Gateway of Elite Chinese Universities: A Genre Analysis of the 'About' Webpages 
(Askehave \& Nielsen, 2005, p. 124). The first page of the other four universities' "About" webpages (44\%) is just the first sub-page displayed in the "About" navigation menus, in other words, there is no main page designed for those "About" webpages: HIT, PKU, SJTU and XJTU.

A sub-page is "a clickable object which allows the navigator to go from one place to another on a webpage/ website" (Askehave \& Nielsen, 2005, p. 132). As shown in Table 1, twenty-two types of sub-pages with a total number of fifty-four were identified on the "About" webpages of the nine universities. Different universities share sub-page categories that offer similar information and content; however, the headings may be used differently. For example, both FDU and ZJU have a section to introduce their history, the terms of "History" and "ZJU's history" are employed respectively. In this regard, the term that more explicitly signifies the content will be used to refer to the sub-pages which occur on different "About" webpages.

Table 1

Sub-pages of the "About" Webpages

\begin{tabular}{|c|c|c|c|}
\hline Sub-pages & Obligatory/ Optional & Frequency & Percentage \\
\hline Introduction & Obligatory & 9 & $100 \%$ \\
\hline Administration & Low optionality & 7 & $78 \%$ \\
\hline History & Medium optionality & 6 & $67 \%$ \\
\hline Message from the president & Medium optionality & 6 & $67 \%$ \\
\hline Facts and figures & Medium optionality & 6 & $67 \%$ \\
\hline Visiting university & High optionality & 3 & $33 \%$ \\
\hline Identity & High optionality & 2 & $22 \%$ \\
\hline Past leadership & High optionality & 2 & $22 \%$ \\
\hline International collaborations & High optionality & 1 & $11 \%$ \\
\hline View of HIT & High optionality & 1 & $11 \%$ \\
\hline HIT Times & High optionality & 1 & $11 \%$ \\
\hline Message from the CUC & High optionality & 1 & $11 \%$ \\
\hline SJTU Today & High optionality & 1 & $11 \%$ \\
\hline International student services & High optionality & 1 & $11 \%$ \\
\hline Life@ SJTU & High optionality & 1 & $11 \%$ \\
\hline Administrative departments & High optionality & 1 & $11 \%$ \\
\hline Library & High optionality & 1 & $11 \%$ \\
\hline Museums & High optionality & 1 & $11 \%$ \\
\hline Contact us & High optionality & 1 & $11 \%$ \\
\hline Current leadership & High optionality & 1 & $11 \%$ \\
\hline $\begin{array}{l}\text { Zhejiang university-wide } \\
\text { publications (Journals) }\end{array}$ & High optionality & 1 & $11 \%$ \\
\hline Hang Zhou & High optionality & 1 & $11 \%$ \\
\hline Total: 22 & & 54 & \\
\hline
\end{tabular}

Note. Moves occurring: 100\%: obligatory; $70 \%$ - 99\%: low optionality; $40 \%$ - 69\%: medium optionality; below 39\%: high optionality (Mulken \& van der Meer, 2005; Suen, 2013)

The Hypertextual Gateway of Elite Chinese Universities: A Genre Analysis of the 'About' Webpages 
In the dataset, there is only one obligatory sub-page, Introduction, while all the other pages are identified as optional. One sub-page is classified as low optionality, Administration; four sub-pages are classified as being medium optional: History, Message from the President, Facts and Figures, and Identity. Another sixteen subpages found are considered as showing high optionality in that the majority of them are just shown in one university's "About" webpage. This finding reveals that the "About" webpages, as a sub-level document of a website discourse, is concerned with the dynamic interaction between discourses and flexible hypertextual practice (Bhatia, 2010). It is different from the top-level homepage of a website which performs overall consistent generic structures, content, and form (Askehave \& Nielsen; 2005; Cheng, 2016; Cheong, 2013; Lam, 2013; Suen, 2013). Complexity is a pervasive phenomenon that it is manifested in different types of information and in different parts of the same web context. This complexity if further accentuated in the Information Age (Bhatia, 2010). Nevertheless, the "About" webpage still implies some similar pivotal information which substantiates a preferred way of organising the webpage text with the most important information (i.e. the obligatory and medium-optional sub-pages).

\section{Communicative Purposes of Rhetorical Moves}

In order to analyse the "About" webpages methodically and systematically, the analysis in this study was done according to grid sections starting from the top (left to right) to the bottom (left to right) of the webpages. Based on the content, form, functionality and communicative purposes of the elements found on the "About" webpages, thirteen rhetorical moves were identified (see Table 2). The communicative purpose constitutes the rationale for the genre that means what authors try to accomplish in a social context, thus it triggers a particular text structure and a set of conventionalised verbal and visual rhetorical strategies (Swales, 1990). These thirteen rhetorical moves are classified into three communitive purposes as (1) Informative purpose: to provide largely factual information about the universities; to inform the public about the academic programmes/ facilities offered at the universities; (2) Promotional purpose: to introduce and offer products of the university and promote the university as an academic institution; (3) Social purpose: to establish and strengthen a personal and close relationship with the webpage readers; to foster the formation of a discourse community between the university webpage and the actual/potential readers; (Lam, 2013; Osman, 2008).

Table 2

Communicative Purposes of Rhetorical Moves of the "About" Webpages

\begin{tabular}{|c|c|c|c|c|c|}
\hline Rhetorical Move & Prop & Steps & IP & PP & SP \\
\hline $\begin{array}{l}\text { Identifying the } \\
\text { institution }\end{array}$ & $100 \%$ & & $\mathrm{~V}$ & & \\
\hline $\begin{array}{l}\text { Establishing closer } \\
\text { relationship with }\end{array}$ & $100 \%$ & $\begin{array}{l}\text { Users' options } \\
\text { Welcome/ Greeting }\end{array}$ & & & $\begin{array}{l}v \\
v\end{array}$ \\
\hline
\end{tabular}

The Hypertextual Gateway of Elite Chinese Universities: A Genre Analysis of the 'About' Webpages 
audience

\begin{tabular}{|c|c|c|c|c|c|}
\hline $\begin{array}{l}\text { Attracting readers' } \\
\text { attention }\end{array}$ & $100 \%$ & $\begin{array}{l}\text { Motto/Slogan } \\
\text { Visual pictures }\end{array}$ & $\mathrm{v}$ & $\begin{array}{l}\sqrt{ } \\
v\end{array}$ & \\
\hline Indicating content & $100 \%$ & & v & & $\mathrm{v}$ \\
\hline & & History & $\mathrm{v}$ & $\mathrm{v}$ & \\
\hline & & Social status & $\mathrm{v}$ & $\mathrm{v}$ & \\
\hline Establishing credentials & $100 \%$ & Teaching \& research & $\sqrt{ }$ & v & \\
\hline & & Alumni & v & v & \\
\hline & & Internationalization & 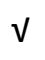 & v & \\
\hline & & Achievement & v & v & \\
\hline Targeting the market & $100 \%$ & Mission statement & & $\sqrt{ }$ & \\
\hline Locating the institution & $100 \%$ & Location/Maps/Campus & $\checkmark$ & & \\
\hline & & Transportation & & v & \\
\hline & & Describing the service & $\mathrm{v}$ & V & \\
\hline Offering information & $100 \%$ & Justifying the service & v & $\mathrm{v}$ & \\
\hline about service & & $\begin{array}{l}\text { Endorsing value of the } \\
\text { service }\end{array}$ & v & v & \\
\hline & & $\begin{array}{l}\text { Indicating value of the } \\
\text { service }\end{array}$ & $v$ & & \\
\hline $\begin{array}{l}\text { Giving related } \\
\text { information link }\end{array}$ & $78 \%$ & & v & & $\checkmark$ \\
\hline Supporting visuals & $100 \%$ & & v & & \\
\hline $\begin{array}{l}\text { Detailing administrative } \\
\text { information }\end{array}$ & $78 \%$ & & $v$ & & \\
\hline Soliciting responses & $100 \%$ & & $\mathrm{~V}$ & $\mathrm{~V}$ & $\mathrm{v}$ \\
\hline
\end{tabular}

Note. IS: Informative purpose PS: Promotional purpose SS: Social purpose

Prop: percentage proportion over total nine "About" webpages;

Moves are listed largely in the usual order of appearance sequence.

It is worth noting that one single rhetorical move may be identified and classified into more than one of the four key communitive purposes, as a move may achieve more than one function at a time and these communicative functions may at times partly overlap (Lam, 2013; Suen, 2013). According to the main theoretical framework for the generic analysis of Osman (2008), only the dominant communicative purpose(s) was/were identified for each rhetorical move in this investigation, which are shown in Table 2. Eleven (85\%) moves achieve the informative purpose that they provide information about the universities from multi-perspectives. Only two moves (15\%) do not show the informative features, namely Targeting the market and Establishing closer relationship with audience. It shows that the information provision is the primary concern and function of the "About" webpages. The universities tend to provide factual information, and there is a predilection of presenting carefully curated details and strategical verbal descriptions with a purpose to maximise their appeal to the target readers, thereby to potentially accomplish the communicative purpose of being promotional (Bhatia, 2013). Being different from other genres, the "About" webpages of Chinese 
universities is therefore presented in a "mixed form" (Bhatia, 2004, p. 11) that they are employed with multiple strategies so as to achieve multifaceted communicative purposes.

The promotional purpose is realised via six moves (46\%). It is observed that the promotional and informational purposes are frequently mixed, especially in the move of Establishing credentials, which indicates that the genre of universities' "About" webpages strategically blurs the lines between describing and selling (Teo \& Ren, 2019). The less-than-half promotional feature validates that the global marketdriven ideology does not privilege the "About" webpage construction of Chinese universities. On the other hand, four moves fulfil a function to strengthen the relationship with the readers, namely social purpose (Lam, 2013): Soliciting responses, Establishing closer relationship with audience, Indicating content structure, and Giving related information link. These moves are purposively used to ensure webpage readers feel at "closed" and convince them that the university tries to do its best to meet their needs and help them enjoy the webpage reading.

The phenomenon of "marketisation" indeed contributes to the hypermodal and hypertextual construction in the web genres of higher educational institutions. In the highly commercialised process of globalisation, universities are forced to marketise themselves as if they were "ordinary business competing to sell their products to consumers" (Fairclough, 1993, p. 141). As such, the webpages of the universities show more promotional features than past, which highlight university's identity, vision, reputation, and the vibrant campus life via the deployment of multimodal resources (both visually and verbally) (Zhang \& O'Halloran, 2012). In order to appeal the elite students, universities make great effort to promote their value and quality by having series of promotional moves in their web genres as a simultaneously effective tool to extend the local market to the world. These promotional and corporate forms of C9 League's online webpages have expanded and shifted from elite education to a diversified system of education to increase the international reputation in order to achieve the government's goal of questing world-class universities (Yang \& Xie, 2015).

As such, the Chinese universities, at least for these nine elite universities, pledge allegiance to their public attribute whose core value is to serve China's higher education and society (Ouyang, 2004). However, the promotional features revealed by the moves exhibit that they are not impervious to the global forces and international marketisation that are transforming education into a corporate-like context. Chinese universities are no longer perceived or work merely as an ivory tower or a base for knowledge dissemination, but have become a place to promote their prestigious image and brand themselves, with a purpose to compete with peer groups in the world. What is worth noting is that although the Chinese universities organise the web genres, represented by the "About", with a similar intention as many marketising higher educational institutions in the word, the dominant function relates to factual information presentation. In other words, the universities in China, such as the C9 League, undergo a lower degree of marketisation compared with other social contexts (Kheovichai, 2014; Morrish \& Sauntson, 2013).

Table 2 suggests that this web genre is relatively stable in its internal rhetorical components, which is shown by the fact that the majority of the move 
categories identified (eleven out of thirteen) are obligatory and occur in all the nine "About" webpages. It may be interpreted that the designers of universities' "About" webpages commonly follow some conventions and possibly utilise some instructional templates in the process of producing this web discourse to speed up the publishing process and to maintain a level of structural consistency. Apart from the internal stability of used move types, some moves are found to be frequently placed at a fixed position, especially at the top (e.g. Identifying the institution and bottom (e.g. Soliciting responses parts of the webpages. The positional features in certain move types will be exemplified when each move type is discussed in the following discussions. By contrast, rhetorical variability in certain move types is observed in the findings. First, ten moves/steps in Osman's $(2005,2008)$ original rhetorical structure of universities' brochures were also identified as constructing "About" webpages of universities, whereas, six moves were found as rhetorical components of this university web genre instead of being deployed in persuasion-oriented genres in the print form. The analysis of the thirteen rhetorical moves uncovered several linguistic and non-linguistic features that contribute to the hypertextual and multimodal construction of the "About" webpages, which are discussed in detail in the following sections.

\section{Rhetorical Moves of the "About" Webpages}

\section{Identifying the institution}

The first move of all "About" webpages is to identify the university which aims to create university's identity thus shape its positive image. This move is realised by showing universities' names (verbal) and logos (visual) (see Figure 2) which jointly define the visual identity of a university (Idris \& Whitfield, 2014) and capitalise on a brand's visual distinctiveness in the market (Mijan, Noor, \& Jaafar, 2020). When audience browse other webpages, the university logo and name can be activated as a link to help them return to the homepage and orient themselves without getting lost on the website with numerous hypertextual resources (Pott, 2007), which are mainly intertextually linked within the "About" webpages.

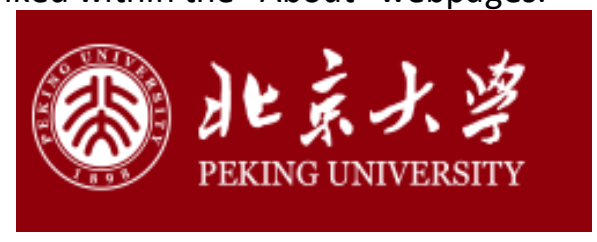

Figure 2. Identification of PKU

Five universities use a combination of graphic symbols with both Chinese and English names in their logos (i.e. SJTU, THU, USTC, THU, ZJU), however, four universities just combine graphic symbol and English name as their logos (i.e. FDU, HIT, NJU, PKU). In contrast, the logotype and icotype are not used by the universities in which the logos just exclusively presented through letters and numerals, or graphics (Heilbrunn, 1997). It indicates, in fact, that all universities' logos are multimodal in nature and different semiotic systems, graphics and linguistic features are 
encompassed (Landa, 2006). In terms of placement, all the logos and names are nearly merged and joined on the left corner of the top row on the websites. This ideologically most salient position is supposed to lead to easy recognition of the universities (Kress \& van Leeuwen, 2006). The audience are swayed to browse the top of the screen first before looking down for further details of the webpages, and the logo notifies them about the identification of the institution they are focusing (Suen, 2013). Therefore, the obligatorily used logo and name are considered as the first move of the universities" "About" webpages.

It indicates that they work together and take a salient position in the already-known part as the nucleus of the information to audience. The closer distance of these two components in one part maintains its cohesion and the two visual elements are still perceived as a cohesive whole in identifying a university. In specific, logos are all placed at the left side of the universities' names (see Figure 2), it is plausible to interpret that the logo is full of graphic features so that easily draws reader's immediate attention than the written language to identify the universities, and as a consequence, it deserves the first attention of audience. The Chinese names are vertically placed above the corresponding English names at almost the same length. Apparently, the Chinese names realise the communicative purpose of drawing reader's attention in the form of large font size and through occupying more than three quarters of the semiotic altitude at upper salient position. Additionally, the name presented in the first language of the university's social community is considered as more paramount to identify its presence, thus the Chinese name is positioned on the upper section showing ideal and thoughtprovoking information for the viewers (Kress \& van Leeuwen, 2006). The English names located on the bottom are in smaller font size, which suggests that it contains secondary information supporting the main message of identifying Chinese universities. In general, typographic meaning potentials are more communicated in Chinese names that are vertically oriented in traditional calligraphy as well spaced out, taking up more space, which functions to attract more reader's attention and connotes elegance and confidence of the universities. The universities' English names are relatively light in weight with regular fonts which are more likely to be print style with an upright typeface, suggesting formality. Furthermore, the letters are connected in neither too tall nor too squat manners to depict a formal image of the universities (Machin, 2007).

This move of identifying the institution is imperative to the validity and integrity of the official websites of the national universities. This is because there are numerous university websites, including key or non-key, public or private, on the Internet to provide university information. The prospective online visitors are more likely to obtain information confidently from the official webpages of the C9 League universities that are supervised by the Ministry of Education. Hence, identifying the official university image can build trust and credibility among audience.

\section{Establishing closer relationship with audience}

This move functions to strengthen the relationship with the webpage visitors by making them feel comfortable and user-friendly when accessing information on the 
webpages. A variety of elements are incorporated in the "About" webpages to convince the readers that the universities are trying their best to fulfill their requirements. The elements realising this move are frequently placed on the top right corner above the navigation menu, which is the uppermost site of the webpages. However, some elements such as contact information may also be located at the bottom part of the webpages. As seen from the following Figure 3, the majority of universities $(n=8)$ employ various elements with a purpose to cater to special users, assist readers in viewing the webpages and information retrieval, and provide relevant contact information that may make the potential readers stay more comfortable (Cheong, 2013). However, USTC has only one "Search" channel to help readers search for information by inputting key words.

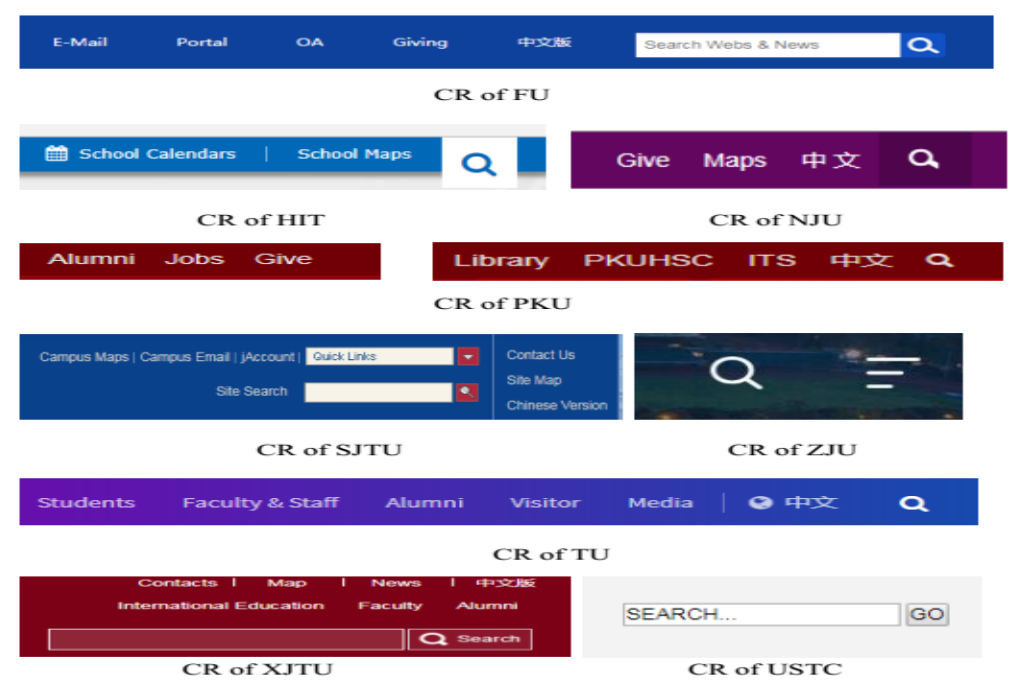

Figure 3. Elements of Establishing Closer Relationship with Audience

A total of 23 types of elements are used to strengthen the relationship with online audience (see Table 3). Among them, the "Search" option $(100 \% / n=9)$ is used as an obligatory one to assist the visitors to receive information that is tailored to their interests and needs, thus saving the time spent on looking at information that they may not be interested in. Webpage readers may look for someone who claims accountability and responsibility for the content thus the possibility of contacting the webpage is considered as a crucial strategy to strengthen the relationship with potential visitors. This may account for why all the nine "About" webpages provide their "Contact" options $(100 \% / n=9)$, such as mailing address, telephone number, fax, E-mail, social networking software (microblog, WeChat, Facebook, Twitter, etc.) at the top or bottom of the webpages or in the Contact or Contact Us hyperlinks. Besides, the language option (69\%) that transfers to Chinese language (in English webpages) is shown on six "About" webpages (67\%) to satisfy reader's language preference. This also contributes to widening the potential market for the webpage readers. The school map is presented on five universities" "About" webpages (56\%) via pictures and details of campus. The majority of the elements are highly optional with a minimal frequency (see Table 3). Thus, a large degree of variability in this 
move elements is disclosed when the webpages attempt to enhance the usability and create a reader-friendly web interface.

Table 3

Elements of Establishing Close Relationship with Audience

\begin{tabular}{|c|c|c|}
\hline Elements & Description & Frequency \\
\hline Search & Searching particular content & 9 \\
\hline Contact & $\begin{array}{l}\text { Providing contact information (Email, phone, } \\
\text { fax, mailing address, social networking } \\
\text { software) }\end{array}$ & 9 \\
\hline Language option & Chinese language option & 6 \\
\hline School Map & Showing school map and campus views & 5 \\
\hline Giving & Collecting donation & 3 \\
\hline Alumni & Collecting information about alumni & 3 \\
\hline Quick links & Links to other contents & 2 \\
\hline $\begin{array}{l}\text { Faculty } \quad \text { Staff/ } \\
\text { Faculty }\end{array}$ & Providing Information about faculties & 2 \\
\hline Portal/ OA & Link to another webpage & 2 \\
\hline School calendar & Describing important days of the university & 1 \\
\hline Time & Showing time & 1 \\
\hline Jobs & Providing information about jobs & 1 \\
\hline Library & Providing information about the library & 1 \\
\hline PKUHSC & Describing an important department & 1 \\
\hline Internet service & $\begin{array}{l}\text { Linking to another webpage related to } \\
\text { Internet }\end{array}$ & 1 \\
\hline Login & Student login page & 1 \\
\hline Student & Descriptions on students' life and study & 1 \\
\hline Visitor & Providing information about visiting & 1 \\
\hline Media & Showing photos, news and press & 1 \\
\hline News & $\begin{array}{l}\text { Providing the latest news regarding the } \\
\text { university }\end{array}$ & 1 \\
\hline $\begin{array}{l}\text { International } \\
\text { education }\end{array}$ & $\begin{array}{l}\text { Providing information about international } \\
\text { education }\end{array}$ & 1 \\
\hline Home & Homepage link & 1 \\
\hline Apply & Leading to information about application & 1 \\
\hline
\end{tabular}

In terms of the presentation mode, a few visual and graphic elements are employedto enhance web visibility. Eight universities use the icon of a magnifying glass $a$ visually indicate the search option. Meanwhile, two universities present icons of social networking software (WeChat, Facebook, etc.) to solicit reader's responses. This establishing hypertextual linkage to social software occurs at the bottom of the webpages. Using these multimodal elements that are familiar to readers in their digital social life helps persuade them to activate the hyperlinks and transform web reading into a kind of social interaction with the universities. The semiotic potential of hypertextuality has been recognised. Nonetheless, the most commonly used elements tend to be presented via verbal resources, which means 
the web visitors read what is displayed on the webpages. These utilities facilitate website accessibility and make navigation of the webpage easier for readers to access contents and obtain relevant information.

A closer relationship with audience is also strengthened by adopting a conversational style to create a friendly, intimate and interactive approach. In a genre, an egalitarian relationship between the interlocutors can be created by the use of "speech-like forms in writing" (Fairclough, 1992, p. 204; Teo \& Ren, 2019). This feature of conversational discourse is especially evident in the opening lines of the personal speech. For example in the following Extract 1 , the welcoming remarks at the beginning of the president's speech functions as a colloquial yet polite expression which indicates formality and mimics the tenor of a conversation to establish a friendly and warmly welcoming tone, thus strengthen the relationship between the readers and the president who represents the university. This can be understood as an attempt to imitate the "customer-oriented" discourses in marketing, to draw readers to the university and can be seen as an instantiation of advertising discourse commonly used in the tourist industry (Askehave, 2007; Teo \& Ren, 2019, p. 10). Another salient feature of conversational discourse of simulating a close relationship between the university president and readers is found in the closing remarks of the president's speech. As exemplified in Extract 2, the appreciative expressions (e.g. thank you) and invitation (e.g. let's work together...) with the use of the exclamation marks further encode a feeling of warmth and goodwill.

1. Welcome to Shanghai Jiao Tong University. (SJTU)

2. We thank you for your attention and look forward to your arrival! Let's work together for a better future! (NJU)

This type of speech-like form in writing is identified in the sub-page named as Message from the President, which is included in six universities' (67\%) "About" webpages (i.e. NJU, PKU, SJTU, THU, XJTU, ZJU). The high frequency of this sub-page in the hypertextual construction of the "About" webpages is accounted as that web genres are not only related to communication, but also signify socialisation in which the community is rooted in (Hamid, 2016). China is identified as a high power distance culture. The value of respect for superiors in hierarchical social relationship especially those in honorifics and titles is reflected in using their statements as endorsement in Chinese universities (Ahmed, Mouratidis, \& Preston, 2009; Xiong, 2012).

\section{Attracting reader's attention}

This is usually realised by a combination of verbal, visual and/or audiovisual elements to make audience to stay on the webpages (Askehave \& Nielsen, 2005). First, three universities (NJU, USTC and ZJU) present the university mottos on the "About" pages to attract reader's eyes. Meanwhile, the term "spirit" is alternatively used along with mottos by NJU and ZJU to fulfill the eye-catching function. As Osman (2008, p. 64) mentioned, the majority of the universities "use the motto inscribed on them as the motto represents the culture or the way of life in the 
university." The purpose of stating the motto or spirit is to establish a positive image of the university thus to intensify the promotional effect. These mottos or spirit imply that the universities inherit excellent culture and contribute to offer qualified service that enables potential students to experience a fulfilling education. As shown in the following two examples, USTC motto is presented in Chinese calligraphy via visual picture, and ZJU motto and spirit are shown in English translation. Both verbal and visual modes display the words in a symmetrical structure, in which the rhetorical function is to enhance the memorability and literary aesthetics.

3. The University Motto: Zhejiang University encourages all its faculty members and students to follow the spirit of "pursuing the truth, being rigorous and earnest, exerting oneself for never-ending progress, and pioneering new trails". In short, the university motto is "Seeking Truth and Pursing Innovation". (ZJU)

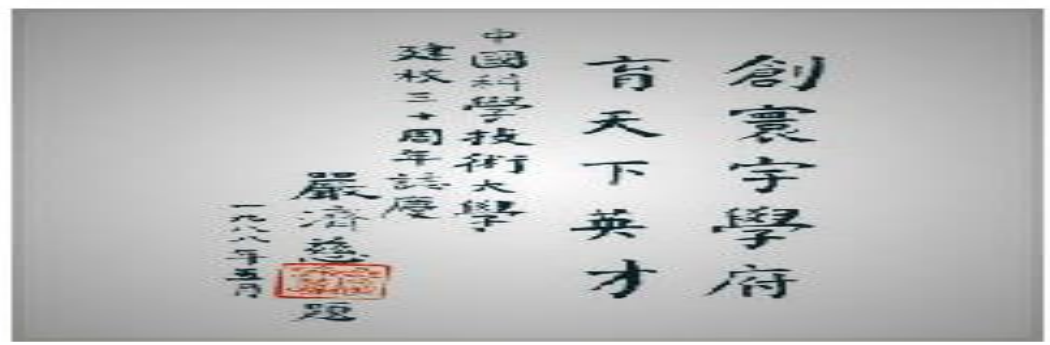

Figure 4. Motto of USTC

Another rhetorical strategy realising the move to Attracting reader's attention is the use of visual elements. The semiotic resources found include static visual pictures with meaning potentials, and graphics that make the webpage visually attractive and interesting; and animations such as videos. In the "About" webpages, visual pictures (100\% or 9/9) fulfill the eye-catching function partially through their dominant locations (on top and middle parts) and relatively large size. At the same time, visual pictures selected are vivid in color to create a stunning impression on the readers. To further increase the visual appeal, the universities often employ not one but several aesthetically pleasing visual images within different sub-pages so that multiple views of the universities can be shown.

Visual images, on the "About" webpages, mainly achieve the conceptual meaning (participants are concerned with class, structure, meaning) ( $n=40 / 66 \%)$ and narrative meaning (unfolding actions and events, processes of change, transitory spatial arrangements) ( $n=21 / 34 \%)$ (Kress \& van Leeuwen, 2006, p. 79). Specifically, the conceptual meanings conveyed by the visual images are bound up with the "symbolic" ( $n=39 / 97.5 \%)$ and "analytical" ( $n=1 / 2.5 \%)$ perspectives. The symbolic meanings of the visual pictures shown on the "About" webpages are classified into four categories: (1) portraying the cultural value and long-established history of the university ( $n=20 / 51 \%)$; (2) depicting the graceful campus and harmonious environment ( $n=13 / 33 \%)$; (3) showing modernisation of the university $(n=6 / 15 \%)$; and (4) depicting grandeur of the university $(n=4 / 10 \%)$. In regard to 
narrative representation, it is optionally expressed since seven (78\%) "About" webpages include this kind of visual pictures. The main narrative contents are related to university activity ( $n=7 / 33 \%$, e.g. conference, ceremony), extracurricular activity ( $n=5 / 24 \%$, e.g. discussion, selfie), studying activity $(n=5 / 24 \%$, e.g. reading in the library, class attendance) and research activity ( $n=4 / 19 \%$, e.g. fiddling with chemicals, discussion in laboratory). The examples of visual images that realise meaning potentials are shown in Appendix 1.

The "About" webpages increase reader's interest by evoking an atmosphere of a vibrant but harmonious university environment that presents themselves as cherishing historic traditions and at the same time keeping pace with modern development. This indicates that the universities aim to establish a prestigious image as elite-class in the global education circle, both working as inheritors of history and culture as well contributing to advanced modern education. The frequently used close-up and medium shots pictures invite the readers to engage in the colorful campus life at the universities. Furthermore, the visual pictures involving study and research activities reinforce the message of the university vision of disseminating knowledge.

\section{Indicating content structure}

The communicative function of presenting "informative" tables of contents and providing access to the website is realised by "links" which tie together the information chunks into a web structure. The hypertextual navigation route or menu is an inherent property of the web-mediated genres (Askehave \& Nielsen, 2005). The functional value of navigation modes is concerned with using structural links to organise the information on the webpages hierarchically, as well as guiding the readers to know what should they know more about. The webpages can chart the users' direction of their information access and identify where the users have moved in the webpages. Instead of providing the readers with a complete overview of the entire site, navigation menus present a selection of topics which range from the names of very broad topic categories to more elaborate leads.

All the "About" webpages include navigation menus which are classified into two categories. One is the navigation menu that provides access to the entire site, which indicates very general topic categories at the upper levels of the website (hereby referred to as homepage navigation menu). As shown in Figure 5, the homepage navigation menu incorporates "Home", "About" "Schools", "Research", "Faculty", "Admission", "Services", "Library", "News". It is horizontally positioned at the upper section of the webpages. This placement leaves the homepage navigation menu with a particular high information value as being ideal and salient (Kress \& van Leeuwen, 2006), which is crucial as the navigators can easily have access to an overview of the main topics covered on the entire university website (Askehave \& Nielsen, 2005).

"About" navigation menu just provides access to specific information within the "About" webpages. As demonstrated in Figure 5, there are two sub-pages encompassed in USTC's "About" webpage, namely "USTC Introduction" and "Administration". All the nine universities have "About" navigation menus, in which 
six are presented vertically (FDU, NJU, PKU, SJTU, USTCC, XJTU) while three horizontally (HIT, THU, ZJU). In general, the "About" navigation menus are frequently located at the upper or middle parts of the webpages, which accounts for the information value that the mid-upper section tends to convey much practical and specific information for the viewers (Kress \& van Leeuwen, 2006). Both types of navigation menus are static. Linguistically, they are realised by a noun or noun phrase (as the terms shown in Table 1 above), which reveal a descriptive nature as the function to bring the audience to identify information topics. As mentioned above in Table 1, the "About" navigation menus of the nine universities are diversified, the choice of topics presented in the navigation menus is governed by what the universities believe will satisfy the information need of the readers when they consult the webpage.

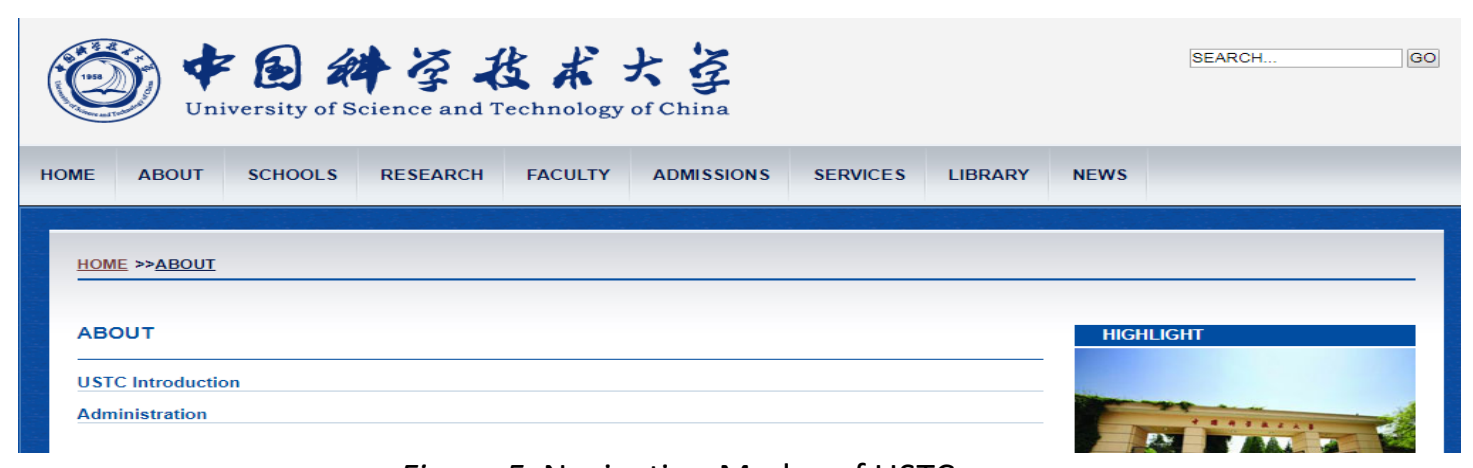

Figure 5. Navigation Modes of USTC

\section{Establishing credentials}

In the promotional genres, the function of establishing credentials is obligatory to fulfill the needs of the potential customers and build company's reputation in the market (Bhatia, 2013). In university discourses, the universities mainly provide objective information, present carefully curated details, and organise them strategically so as to maximise their preponderant aspects thus appeal to their target readers (Teo \& Ren, 2019). By invoking notions of excellence, both text description (verbal strategy) and visual images with figures (visual strategy) are deployed by the universities. What is worth noting is that the universities have a penchant for depicting excellence in the obligatory sub-page, Introduction ( $n=9$ / $100 \%$ ), in which the credentials of the universities are established by foregrounding of particular attributes or qualities deemed desirable to prospective students.

The positive university profile is frequently construed by its academic excellence in teaching and research. The straightforward step showcasing the academic quality is that the universities either list the faculties/research-centers or the academic programmes offered. Meanwhile, the large number of students, teaching staff and renowned academics also enhance the positive image of the university and the academic capacity that it empowers the prospective students to have access to (see Table 4). 
Table 4

Realisations of Establishing Credentials

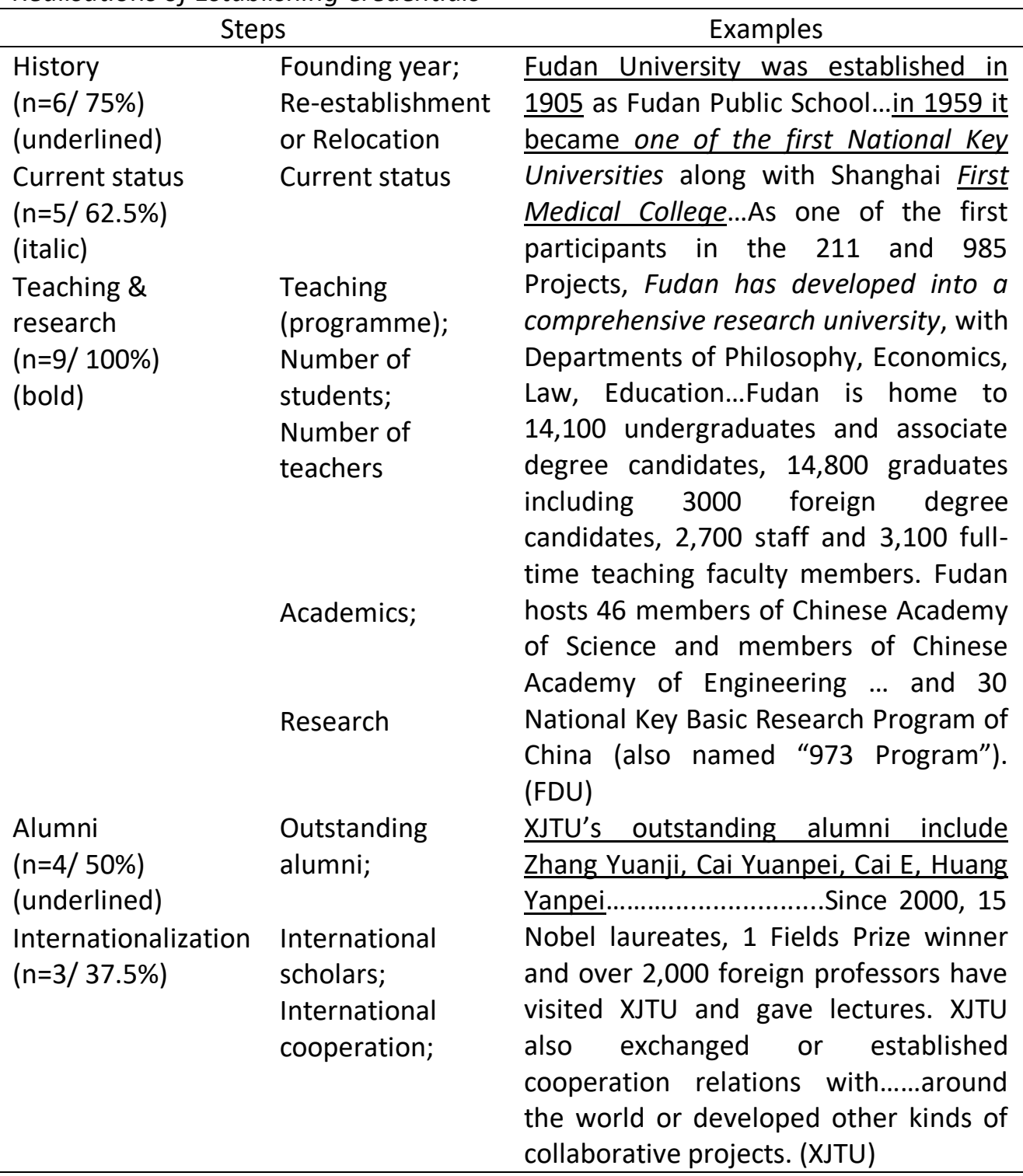

Another attribute that the majority of the universities focus on is tracing the long historical background, implying a rich heritage. This foregrounding is syntactically realised by positioning the founding year encoding the university's long history at the beginning of the introductions (e.g. "1905" in Table 4). In some cases, the re-establishment or relocation of the university is also recounted to amplify its long historical development, such as in Table 4, FDU emphasises "in 1959 it became one of the first National Key Universities along with Shanghai First Medical College".

Excellence is also ascribed to current status or reputation that the universities directly allude to. The universities tend to allude to governmental affiliation, such as "the 211 and 985 Projects" in Table 4. In addition, the remarkable quality is frequently evident through the process of deploying positive appraisal 
inscriptions (e.g. national, key, first, comprehensive in Table 4) to intensify the university's prestigious social status and influence.

Instead of foregrounding the extensive number of internal students and names of academics, some universities lay emphasis on alumni to reinforce the value of having a worldwide reserve of talents as part of the branding strategy. Many universities emphasise the names of outstanding alumni rather than showcasing general numbers. As shown in Table 4, a list of renowned alumni's names is presented to show the readers that the university has cultivated many of the country's most illustrious talents and contributed to the nation's achievements. Internationalisation is valorised and keenly quested by the Chinese universities (Yang \& Xie, 2015), therefore the level that the universities engaged in the international community is also considered as a hallmark of their excellence. The universities attach value to the number of the international scholars they have and international cooperation they participate in (see Table 4).

The semiotic resources are employed by some universities as a purposive strategy to establish their credentials. In Figure 6 , logos of some academic ranking systems (e.g. QS, Global Nature Index) are presented on the webpage to intensify the academic excellence of NJU. The quality of university's academic teaching is strengthened through the numbers of full-time students at undergraduate, master, doctoral and international levels, which are presented via the use of graphics. The visual images fulfill the eye-catching function through their distinctive graphic design and vivid colour, creating a stunning impression on the webpage readers.

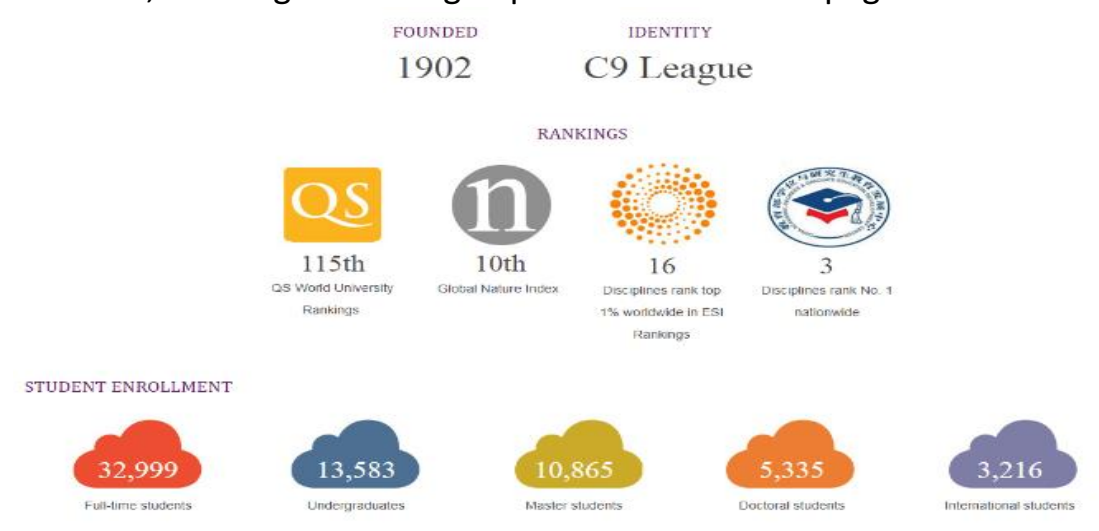

Figure 6. Visuals Illustrating Achievements of NJU

\section{Targeting the market}

This move is previously identified as targeting the market based on the communicative functions of the mission statements (Osman, 2008). In other words, this move provides information about what type of university it is and what it does (Falsey, 1989) at the same time highlighting the positive factors in the university. Therefore, in professional discourses, targeting the market is a corporate strategy (Sauntson \& Morrish, 2011). In the "About" webpages, this rhetorical move is more likely to be compositionally presented at the last paragraph of the introductory texts which functions as the summary of the introduction. It is utilised as a strategy to bolster the university's quality and attractiveness in the minds of the readers, i.e. 
prospective students and their parents. Besides opting to use mission statements and explicitly targeting objectives of the universities, many of the universities demonstrate a global vision and university's philosophy (i.e. motto/spirit/ tradition). Targeting the market of the universities is observed to provide information about what and how they can contribute to the public in terms of tertiary education and societal development, as underlined in the following example:

4. ...the school has made outstanding contributions to the country by developing talent, innovating in science and technology, carrying forward civilisation, and serving society. Students and teachers of Fudan always keep in mind the school motto "Rich in knowledge and tenacious of purposes..." main the school spirit of "civilised...", practice the school traditions of being "hardworking...", and develop the Fudan spirit of "patriotic service..." They make great contributions to the liberation and development of the people, the construction and development of the nation, and civilisation and progress of society. (FDU)

In Extract 4, the words "contribution", "talent", and "innovating" are used to emphasise the university's contributive achievements of the science and technology which boost the country's foundation. The second sentence uses the university motto and spirit to convince the readers that the university has a good educational culture. The last part summarises its contribution to the liberation and development of people. Therefore, the statement targets the university as a successful comprehensive university with prestigious achievement as well as a contributor in developing the people, country and society.

\section{Locating the institution}

The common strategies used to fulfill this move are providing a textual description on university's geographical location $(n=7)$ or a map $(n=5)$. A textual description is concerned with two perspectives of information: providing the location of the campus (see Extract 6); describing the campus size (see Extract 5) (Osman, 2005). Three univeristies show their campus maps to locate the universities. According to Osman (2005), access to the campus/university also accomplishes this move. In the dataset, three universities describe the ways to access the universities, namely the transportation guide, which is presented in specific hyperlinks (e.g. Useful Traffic Information, Public Transportation; Directions) to evoke curiosity of the webpage readers and further persuade them to visit the universities. All the nine universities offer a full address in the "About" webpages to locate where they are (see Extract 6). As aforementioned, it is also identified as Soliciting responses as it is also the postal address of the university. The university's address is preferred to be provided at the bottom of the webpages where the real information is emphasised (Kress \& van Leeuwen, 2006).

5. The campus, known as "Yan Yuan" (the garden of Yan), is situated at Haidian District in the western suburb of Beijing, with a total area of 
$2,743,532$ square metres (or 274 hectares). It stands near to the Yuanmingyuan Garden and the Summer Palace.

6. Zhejiang University, 886 Yuhangtang Road, Hangzhou, Zhejiang Province 310058, P. R. China. (ZJU)

\section{Offering information about service}

This move refers to the introduction to the service, namely programmes and facilities, offered by the universities. Like the descriptions of credentials, this rhetorical move exhibits the fact that the universities attempt to intensify the value of the service and create a positive identity of the universities. In the present study, this rhetorical move encompasses four micro steps which are derived from the primary analytical model of Osman (2008): (a) Describing the service, (b) Justifying the service, (c) Endorsing the value of the service and (d) Indicating value of the service.

\section{(a) Describing the service}

This is the straightforward way in which most of the universities either list the faculties or the academic programmes offered by the faculties in detail, occurred in eight or $89 \%$ of the "About" webpages. Previous promotional genre studies disclose that the core business of nowadays universities is providing the academic programmes (Osman, 2008). Nevertheless, the description on academic programmes offered by the universities in the "About" webpages reveals informative in nature due to the absence of promotional elements. Apart from teaching, the C9 League universities also sit at the top in the Chinese higher education system with reference to research (Yang \& Xie, 2015). Therefore, research is also one predominant "service" to the students. In the "About" webpages, especially in the introductions, the universities either provide the list of faculties, academic programmes, research institutes/programmes, more specifically, which are clearly described at different degrees and levels (see Extract 7). Some universities also take advantage of using visual resources to list the faculties either in graphic elements or tables (see Figure 6). Not much socio-cultural effect and attitudinal markers have been observed in this rhetorical move. The universities prefer to use numbers to highlight their academic quality. Furthermore, the in-detail explanation of academic disciplines will be shown in particular webpages (e.g. Schools) rather than the "About" webpages.

7. There are 28 schools and independent departments with 70 bachelor degree programmes, 35 doctoral degree programmes of Level I academic disciplines... There are 11 Level I national key academic disciplines... Fudan hosts around 300 research institutes including 5 national key labs...7 "Project 985" Arts and Social Sciences Innovation Bases. (FDU)

(b) Justifying the service

This is realised via the use of both verbal and visual strategies to provide information about the facilities and services available in the universities for both students and staffs. It functions to influence the potential students into believing that the 
university being described has specifically valued quality for them. The main strategy for accomplishing this purpose is to describe various facilities and service available on campus, both academic (e.g. museum, library, laboratory) and non-academic (e.g. clubs, activities), to support the academic programmes. In the following example, the president of THU introduces university's museum, conferences, published reading lists, international forums, to justify that the university is wellrounded both in facilities and academic infrastructure. It is noteworthy that appraisal qualifiers are not often used to flourish the facilities, thus this rhetorical move displays less promotional features when compared with typical promotional genres. The majority of the universities $(n=6 / 67 \%)$ prefer to include this type of content in the introductions. However, some universities may have a specific subpage to elaborately justify the programmes/service, for instance, "Library" and "Museum" in the "About" of SJTU.

8. On September 10, 2016, the Art Museum was officially inaugurated...a recommended Tsinghua reading list has also been released... hosting $\underline{5^{\text {th }}}$ World Peace Forum... (THU)

(c) Endorsing the value of the service

The use of endorsement has become a common practice in the field of branding. In the business world, endorsement could be effective in increasing sales, and subsequent changes in the performance or reputation of an endorser can further benefit the improvement of the institution (Elberse \& Verleun, 2012). In the "About" webpages, endorsements of the quality of academic programmes and achievements of the universities are realised by the recognitions of authoritative persons or institutions. There are two examples shown for each:

9. Chinese President $\mathrm{Hu}$ Jintao sent a letter of congratulations, expressing his hopes that... (FDU)

10. On May 11, the Nature Publishing Group released Nature Publishing Index 2010 China, remarking "a dramatic rise in the quality of research being published by China". (USTC)

In Extract 9, the testimonial congratulation from the President Hu Jintao is shown to reinforce the achievements of FDU. At the moment, President Hu Jintao served as one of the highest leaders in China and he undoubtedly had tremendous authority to confirm the excellence of the university. In addition to the testimonial statements from public figures or relevant authorities, USTC shows the evaluation and ranking released by the Nature Publishing Group which serves as one of the highest authorities in evaluating an individual or institution's research ability (Publons, 2019). Therefore, the testimonial statement of "a dramatic rise in the quality of research being published by China" in Extract 10 endorses the university's research output. Political-leader endorsers and authoritative endorsing institutions can strengthen the endorsing source and universities' brand image as a possible "best". Consequently, the rhetorical function of this move seeks to project the positive image of the universities as forerunners in the academic field. 
(d) Indicating value of the service

The entry requirements to enroll into the different academic programmes, and the fees charged as well as the duration of these programmes indicate the value of the universities and what they provide (Osman, 2008). Nevertheless, stating the value of the university is not a common feature of the "About" webpages since only one university (SJTU) (11\%) notifies the fees charged via a hyperlink "Registration \& Tuition Fees" within the sub-page "International Student Service". Osman (2008) reported different phenomena that the feature of corporatisation in Malaysian public universities is reflected in the production of corporate-like brochures which show the most competitive prices in services. Hence it suggests that the corporatisation level of the universities' "About" webpages is lower than traditional promotional materials.

\section{Giving related information link}

Hypertextual web discourse involves different ways of providing access to the web content. Either the links provide access to the very general topic categories at the upper levels of the website (as generic links or navigation menus) or the links provide access to more specific information at a lower level on the web (specific links), which is identified as a move of Giving related information link. Seven universities provide related information links in their "About" webpages, which are directed to various information (e.g. campus, students, news). Specific links are frequently inserted further down the webpages primarily containing real information and they reveal a changeable nature that the text connected via specific links may change by time which accentuates the dynamic attribute of web-mediated texts as opposed to printed texts (Askehave \& Nielsen, 2005).

The clickable specific links consists of noun clause and noun (see Figure 7) which present the topic and give the viewers an idea of what type of information to navigate behind the links. They are used to make the web context more interesting and informative, especially for those navigators whose way into the webpages is not guided by a particular route, but are more prone to looking for specific links with enticing leads. All the specific links in the dataset are marked as intertextual feature in that they are connected and bring readers to a deeper level of specific information within the same website (Storrer, 1999). These intertextual links are presented in a vertical sequence order, nonetheless, no conventional compositional pattern of specific links is observed in the universities" "About" webpages.

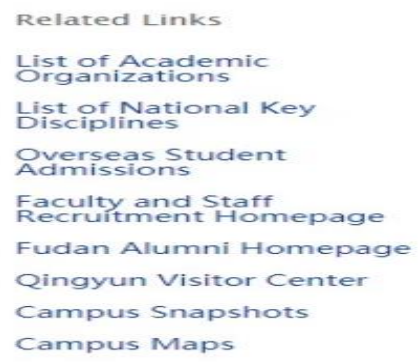

Figure 7. Related Information Links of FDU 


\title{
Supporting visuals (SV)
}

Visuals may be used to assist information presentation on the webpages (Cheong, 2013), for instance, university leader's portrait is placed beside his/her introduction to help the readers further identify the leader. The visual images lacking communicative meta-functions (Kress \& van Leeuwen, 2006) and fulfilling this kind of communicative function are identified as Supporting visuals in the "About" web genres. The example given in Figure 8 is extracted from the navigation menu of $\mathrm{NJU}$, in which the content of this sub-page shows the welcoming message from the current president. The personal image of the president is presented beside the text to partially attract readers' attention and to avoid the boringness that is caused by pure-text webpage reading. On the other hand, it is more likely to make the message integrated with the speaker (i.e. university president).

In China, university presidents are appointed directly by the Ministry of Education of the People's Republic of China (MOE) or the provincial education departments. The president is the head of the university and what they say in the official context can thus be seen as an epitome of the ethos and philosophy of the university (Han, 2014). Therefore, portraits of universities' presidents strengthen their message as an authoritative discourse which signifies the institutional reality. Supporting visuals are frequently observed in the sub-pages of Administration, Message from the President and Past Leadership. These photographs are perceived as demand images which are connected with close shots in personal distance. As displayed in Figure 8, NJU's president in formal suit attempts to establish a kind of imaginary relation with the viewers (Kress \& van Leeuwen, 2006). A horizontal angle of frontality allows the viewers to be directly confronted with, and thus maximally involved with the university web context (Zhang \& O'Halloran, 2012). His direct gaze and courteous smile fill in what he demands from viewers: their identification with and enrolment into the university if they accept his friendliness and warm welcoming.

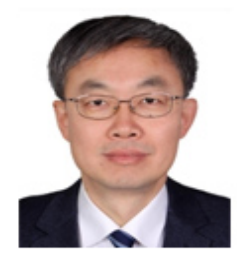

\author{
Message from the President \\ The predecessor of Nanjing University was renowned for \\ its scientific achievements. The emphasis on investigation \\ and the seeking for truth ran through the history of its \\ development..
}

Figure 8. Supporting Visual of NJU

\section{Detailing administrative information}

In the "About" webpages of Chinese universities, the sub-page of Administration has low optionality since $78 \%(n=7)$ of universities have it. In this sub-page, universities' administrative information is provided. All the universities describe the names of administrative positions (secretary, president, etc.), organisations (departments, office, divisions, center, etc.), persons-in-charge, and university leaders. Some universities also describe the responsibility and contact information of the 
corresponding leaders, positions and organisations in order to help readers understand the administrative system of the university. Then the readers are supposed to gain possibly maximum benefits from a university's system and they are able to exploit all of its capacities and service. To increase information comprehension, readers can make contact in order to collect more accurate information. It can be classified as an intertextual mixing of bureaucratic, informative and promotional discourse, which suggests a confluence between bureaucratic powers and high-power social culture. The frequent administrative information as discursive contents is interpreted as a fact that the Chinese universities desire to uphold hierarchical social value (Ahmed, Mouratidis, \& Preston, 2009; Xiong, 2012).

\section{Soliciting responses}

Showing contact information is identified as soliciting responses because it is inferred that the universities expect visitors to respond by contacting them to ask for further inquiries. The universities compete to attract potential customers i.e. students, thus the majority of university promotional genres end with a call to action (Osman, 2005, 2008; Wells, Burnett, \& Moriarty, 2003). There are some subtle tactics used by university promotional genres, however, they are established in specific webpages such as "How to apply", "Further inquiries", "Application" or "Admission" rather than the "About" webpages in universities' websites. The inclusion of this move can be providing universities' postal address, phone number, fax, E-mail address, contact links, software icons (e.g. WeChat), etc. This move is highly consistent with corporate websites which are created with a purpose of "representing a company, selling the company's name, attracting more visitors, generating more business leads, promoting company's products and services, and ultimately, helping to gain more return on investment" (Lepcha, 2006, p. 1).

Having complete contact information is crucial for an institution because sometimes it is difficult to tell if the institution described on a website is really trustworthy or not, therefore, it helps to relieve visitor's worry and maintain the trustworthiness of the web content (van Duyne, Landay, \& Hong, 2003). As shown in Extract 11, a physical address enables the visitors to know where and how to find the university. Similarly, E-mail address, phone and fax numbers are also important rhetorical elements in case the readers need immediate assistance and these contacting methods are more time-saving and convenient (van Duyne, Landay, \& Hong, 2003). Nonetheless, demonstrating the postal address of the university is also used to realise the move of Locating the institution, which will be discussed next.

11. 220 Handan Rd., Yangpu District, Shanghai (200433|Operator: +86 21 65642222_(FDU)

\section{Giving information about the webpage}

This move is realised via stating the copyright and legitimate information of the webpages. In this move, it states the official provider of the information contained in 
the websites, thus to ensure the reliability of the contents and information. The frequent placement of this move is at the bottom of every page. As shown in the following example 12, the copyright statement is preferably established with the format: (Copyright) @ + time of update + University name + (All Rights Reserved). In addition, some universities $(n=2)$ also display the registration of local public security bureau, as shown in the following Extract 13, which plays a pivotal role as part of intensifying the legitimate trustworthiness of the web-owner and content presented.

12. Copyright @ 2016 FUDAN University. All Rights Reserved

13. 京公网安备 110402430047 号 (PKU)

(Translation: Record of Beijing Public Internet Security)

\section{Discussion}

The "About" genre is hypertextual with a relatively high level of multimodality. In this regard, this discourse reveals a high degree of interactivity explicitly displayed through a combination of different modes of communication, most prominently the linguistic and visual resources. Multimodal resources are hypertextually linked across the "About" genre to persuade students to be confident about the universities through the creation of prestigious identity and reader-friendly hyperreading context. The hypertextual web genres enable a non-linear transmission of information. This non-hierarchical system influences and constrains text production and reception on the web content. Thus, hypertext is characterised as a nonsequential rhetorical system. The information offered by the hypertext is not based on how it is produced and structured by designers but on how it is accessed by readers who choose their reading process and thereby create their "own" text in the hypertext system (Askehave \& Nielsen, 2005). This demonstrates not only the reading mode and navigating mode of the hypertextual web are flexible, but also the intra-generic move variations are greatly unfolded.

Admittedly, university discourse is gradually being "colonised" by corporate discourse and possessing attributes that are self-promotional in recent decades (Kheovichai, 2014), the marketisation as well as globalisation indeed drive the Chinese university discourse in the direction to being promotional (Han, 2014; Teo \& Ren, 2019). Nonetheless, this study validates that although the Chinese universities attempt to utilise certain promotional elements by resorting to marketing strategies and brand communication (Mampaey, Huisman, \& Seeber, 2015), state-controlling force is still, at least in the "About" genre, more potent than market-orientated economic influence, as the Chinese universities, especially those at elite level are keen on positioning themselves with reference to bureaucratic and administrative hierarchies via particular rhetorical moves (e.g., Detailing administrative information, Supporting visuals). This resonates with the theorising concluded in the previous study in that marketisation in Chinese higher education needs to be understood on the basis of a bureaucracy-market alliance. In the Chinese social context, the university's traditional value of autonomy and freedom has been 
overwhelmed by the predominant bureaucratic-conversational interaction (Xiong, 2012).

Though the discursive constructions of universities' "About" genre, especially the introductory text, adopts some branding strategies to publicise prestige academic value and brand the universities where the students live in, nevertheless, the conceptualisation of students as customers has not been remarkably empowered to students as other profit-driven discourses (Barnett, 2011). This is owing to the fact that the Chinese universities especially those from elite level are keen on nurturing and educating students, revitalising the country and developing the tertiary education (Ngok, 2008). The Chinese universities are nowadays gradually embracing the global market-driven values while upholding a national instrumentalist ideology. The elite Chinese universities (C9 League) are concurrently massively dependent on governmental economic support and political validation (Teo \& Ren, 2019). However, in the cases of western countries such as in the UK where market revolution has swept into higher education, universities are obliged to engage in self-promotion and marketing more intensively. It is argued that the rhetoric contained within many British universities' discourses (e.g. mission statements) emerge from neoliberalism and do not sit comfortably in the traditional values of university academics (Morrish \& Sauntson, 2013). The interplay between socio-political and socio-economic imperatives at both global and local levels have driven elite Chinese universities to carefully establish a unique, dynamic and complex discursive practice in the process of marketisation and internationalisation.

\section{Conclusion}

By deconstructing the rhetorical structure and probing into the discursive constructions of the "About" webpages of nine elite Chinese universities (the C9 League), this study has shed light on this emerging web genre with respect to revealing a characterisation of rhetorical practice. This study has identified and discussed thirteen rhetorical move types in the generic structure of this web genre and how they are manifested through the interplay between hypertextuality and multimodality. It indicates that the "About" webpage is identified as a mixed genre which is constructed by the elements from other genres such as promotional brochures and corporate homepages, nevertheless, it is characteristic in terms of rhetorical structure, linguistic and multimodal features. The "About" webpage is applied as a multiple-purpose genre which is predominantly informative, while it also discloses a blend of promotional and social communicative purposes through the strategic employment of interdiscursive elements in different rhetorical moves. This study potentially contributes to the theoretical and methodological development of studies in terms of information and communication, with a purpose to enhance the knowledge of the web-mediated genre related to the current global society - higher education institutions. Users also benefit from this study as it increases their awareness of the generic characteristics of university web genres. The rhetorical model of analysis proposed above offers practical and pedagogical insights into how linguistic and semiotic resources can be used when constructing hypertextual texts, especially the "About" webpages. This study was conducted with 
a focus on elite Chinese universities' "About" webpages only. Future investigations are recommended to include hypertextual and multimodal analysis at different sectors other than education and on more web-mediated genres.

Disclosure Statement: The authors declare no potential conflicts of financial interest or benefit with respect to the research, authorship, and/or publication of this article.

\section{References}

Ahmed, T., Mouratidis, H., \& Preston, D. (2009). Website design guidelines: High power distance and high-context culture. International Journal of Cyber Society and Education, 2(1), 47-60.

Allen, R. M. (2017). A comparison of China's "Ivy League" to other peer groupings through global university rankings. Journal of Studies in International Education, 21(5), 395-411.

Askehave, I. (2007). The impact of marketization on higher education genres: The international student prospectus as a case in point. Discourse Studies, 9(6), 723-742.

Askehave, I., \& Nielsen, A. E. (2005). Digital genres: a challenge to traditional genre theory. Information Technology \& People, 16(2), 120-141.

Bano, Z., \& Shakir, A. (2015). Personal pronouns in 'About Us' section of online university prospectus. Journal of Education and Practice, 6(1), 133-139.

Bargiela-Chiappini, F. (2006). Polyphony or pseudo-dialogue? Multimodality, hypertextuality and Internet banking. In G. D. L. Camiciotti, M. Dossena, \& B. C. Camiciottoli, B (Eds.), Variation in business and economics discourse: Diachronic and genre perspectives (pp. 101-114). Rome: Officina Edizioni.

Barnett, R. (2011). The marketised university: Defending the indefensible. In M. Molesworth, R. Scullion, \& E. Nixon, (Eds.), The marketisation of higher education and the student as consumer (pp. 39-51). New York, NY: Routledge.

Bednarek, M. (2014). 'And they all look just the same'?: A quantitative survey of television title sequences. Visual Communication, 13(2), 125-145.

Bhatia, V. K. (2013). Analysing genre: Language use in professional settings. New York, NY: Routledge.

Bhatia, V. K. (2010). Interdiscursivity in professional communication. Discourse \& Communication, 4(1), 32-50.

Bhatia, V. K. (2004). Words of written discourse: A genre-based view. London: Continuum.

Biber, D., \& Conrad, S. (2009). Register, genre and style. Cambridge: Cambridge University Press.

Caiazzo, L. (2014). Emerging conventions in the verbal component of the 'About' page of British university websites. In P. E. Allori, J. Bateman., \& V. K. Bhatia (Eds.), Evolution in genre, (pp. 307-325). United Kingdom: Peter Lang AG

Caiazzo, L. (2013). British and Indian university websites: A corpus-based study of the 'About' page. Retrieved from http://digital.casalini.it/9788864580951

Casañ-Pitarch, R. (2015). The genre "about us": A case study of banks' corporate webpages. International Journal of Language Studies, 9(2), 69-96. 
Cheng, F. W. (2016). Constructing hotel brands: A multimodal analysis of luxury hotel homepages. Ibérica, 31, 83-108.

Cheong, C. Y. M. (2013). A multi-dimensional genre analysis of tourism homepages and web-medicated advertorial. (Unpublished doctoral dissertation). University of Malaya, Kuala Lumpur, Malaysia.

Deuze, M. M. (2001). Online journalism: Modelling the first generation of news media on the World Wide Web. Retrieved from http://firstmonday.org/htbin/cgiwrap/bin/ojs/index.php/fm/article/view/893 $/ 802$

Elberse, A., \& Verleun, J. (2012). The economic value of celebrity endorsements. Journal of Advertising Research, 149-165.

Erhan, S., \& Semiral, Ö. (2010). Conducting preliminary steps to usability testing: investigating the website of Uludag University. Procedia Social and Behavioral Sciences, 2, 890-894.

Falsey, T. A. (1989). Corporate philosophies and mission statements. New York, US: Quorum Books.

Fang, S., Xu, H., Yue, Z., Li, H., Qi, Y., \& Lei, B. (2013). Empirical research of advantage disciplines of C9 League. Chinese Journal of Library and Information Science, 6, 79-96.

Fairclough, N. (1993). Critical discourse analysis and the marketization of public discourse: The universities. Discourse \& Society, 4(2), 133-168.

Fairclough, N. (1992). Discourse and social change. Cambridge, UK: Polity Press.

Fletcher, R. (2006). The impact of culture on web site content, design, and structure: An international and a multicultural perspective. Journal of Communication Management, 10(3), 259-273.

Gervais, B. (2013). Is there a text on this screen? Reading in an era of hypertextuality. In R. Siemens \& S. Schreibman, (Eds.), A companion to digital literary studies, (pp. 183-202). London, UK: John Wiley \& Sons.

Graham, C. (2013). Discourse of widening participation in the prospectus documents and websites of six English higher education institutions. British Journal of Sociology Education, 34(1), 76-93.

Hamid, M. A. (2016). Analysis of visual presentation of cultural dimensions: Culture demonstrated by pictures on homepages of universities in Pakistan. Journal of Marketing Communications, 23(6), 592-613.

Han, Z. R. (2014). The marketization of public discourse: The Chinese universities. Discourse and Communication, 8(1), 85-103.

Heilbrunn, B. (1997). Representation and legitimacy: A semiotic approach to the logo. In W. Nöth (Ed.), Semiotics of the media: State of the art, projects and perspectives (pp. 175-189). Berlin: Mouton de Gruyter.

Idris, M. Z., \& Whitfield, T. W. A. (2014). Swayed by the logo and name: Does university branding work? Journal of Marketing for Higher Education, 24(1), 41-58.

Kheovichai, B. (2014). Marketized university discourse: A synchronic and diachronic comparison of the discursive constructions of employer organizations in academic and business job advertisements. Discourse \& Communication, 8(4) 371-390. 
Kress, G. (2010). Multimodality: A social semiotic approach to contemporary communication. London: Routledge.

Kress, G., \& van Leeuwen, T. (2006). Reading images: The grammar of visual design. (2nd ed.). London, UK: Routledge.

Lam, C. (2009). The essence of "About Us" page with 12 captivating showcases. Retrieved from https://onextrapixel.com/the-essence-of-about-us-page-with12-captivating-showcases/

Lam, P. W. Y. (2013). Interdiscursivity, hypertextuality, multimodality: A corpusbased multimodal move analysis of Internet group buying deals. Journal of Pragmatics, 51, 13-39.

Landa, R. (2006). Designing brand experience: Creating powerful integrated brand solutions. USA: Thomson Delmar Learning.

Lemke, J. (2002). Travels in hypermodality. Visual Communication, 1(3), 299-325.

Lepcha, S. (2006). Importance of website design and development. Retrieved from https://ezinearticles.com/?Importance-of-Website-Design-andDevelopment\&id=357554.

Machin, D. (2007). Introduction to multimodal analysis. New York, NY: Oxford University Press.

Mampaey, J., Huisman, J., \& Seeber, M. (2015). Branding of Flemish higher education institutions: A strategic balance perspective. Higher Education Research \& Development, 34(6), 1178-1191.

Mijan, R., Noor, S. M., \& Jaafar, M. (2020). Exploring strategic branding resources for small and medium-sized brand-oriented companies. SEARCH Journal of Media and Communication Research, 12(1), 29-45.

Morrish, L., \& Sauntson, H. (2013). 'Business-facing motors for economic development': An appraisal analysis of visions and values in the marketised UK university. Critical Discourse Studies, 10(1), 61-80.

Mulken, M., \& van der Meer, W. (2005). Are you being served? A genre analysis of American and Dutch company replies to customer inquiries. English for Specific Purposes, 24(1), 93-109.

Ngok, M. (2008). Massification, bureaucratization and questing for "world-class" status. International Journal of Educational Management, 22(6), 547-564.

Nutter, M. (2009). Best practices for effective design of About Me pages. Retrieved from www.smashingmagazine.com

O'Reilly, M, E, A., \& Newton, D. (2000). The role of university web pages in staff development: supporting teaching and learning online. In The Web: Communication and information access for a new millennium (pp. 222-238). Proceedings of AusWeb2K, the Sixth Australian World Wide Web Conference, Lismore, NSW: Southern Cross University.

Osman, H. (2008). Re-branding academic institutions with corporate advertising: A genre perspective. Discourse \& Communication, 2(1), 57-77.

Osman, H. (2005). Structural organization and socio-cognitive strategies in university brochures: Implications for ESP. (Unpublished doctoral dissertation). University of Malaya, Kuala Lumpur, Malaysia.

Ouyang, K. (2004). Higher education reform in China today. Policy Futures in Education, 2(1), 141-149.

The Hypertextual Gateway of Elite Chinese Universities: A Genre Analysis of the 'About' Webpages 
Pott, K. (2007). Web design and marketing solutions for business websites. USA: A Press Company.

Publons. (2019). Nature publishing group. Retrieved from publons.com/publisher

Sauntson, H., \& Morrish, L. (2011). Vision, values and international excellence: The 'products' that university mission statements sell to students. In $M$. Molesworth, R. Scullion, \& E. Nixon, (Eds.), The marketisation of higher education and the student as consumer (pp. 73-85). New York, NY: Routledge.

Storrer, A. (1999). Koharenz in text and hypertext. In L. Henning (Ed.), Text Imdigitalan Medium: Linguistische aspekte von textdesign, TExttechnologie and hypertext engineering. Opladen: Westdeutscher Verlag.

Suen, O. Y. (2013). Hotel websites as corporate communication. (Unpublished doctoral dissertation). The Hong Kong Polytechnic University, Hong Kong.

Swales, J. M. (1990). Genre analysis: English in academic and research settings. Cambridge: Cambridge University Press.

Tan, G. (2013). The ecommerce authority. Retrieved from www.onlinebusiness.volusion.com

Teo, P., \& Ren, S. (2019). Marketization of universities in China: A critical discourse analysis of the university president's message. Discourse \& Communication, 13(5), 539-561.

van Duyne, D. K., Landay, J. A., \& Hong, J. I. (2003). Design of sites: patterns, principles, and processes for crafting a customer-centered web experience. USA: Addison-Wesley Professional.

Villanueva, L. S., Dolom, M. A. C., \& Belen, J. S. (2018). Genre analysis of the "About Us" sections of Asian Association of Open Universities websites. Asian Association of Open Universities Journal, 13(1), 37-59.

Wells, W., Burnett, J. and Moriarty, S. (2003). Advertising principles and practice. Upper Saddle River, NJ: Pearson Education.

Xiong, T. (2012). Discourse and marketization of higher education in China: The genre of advertisements for academic posts. Discourse \& Society, 23(3), 318337.

Yang, R., \& Xie, M. (2015). Leaning toward the centers: International networking at China's five C9 League universities. Frontiers of Education in China, 10, 66-90.

Yue, W., \& Zhu, J. (2009). A quantitative perspective on the leading role of top universities in China. In Proceedings of 3rd International Conference on WorldClass Universities: The Role of WCU in National Systems (pp. 109-119). China, Shanghai: Center for World-Class Universities.

Zhang, Y., \& O'Halloran, K. L. (2012). The gate of the gateway: A hypermodal approach to university homepages. Semiotica, 1(4), 87- 109.

The Hypertextual Gateway of Elite Chinese Universities: A Genre Analysis of the 'About' Webpages 